\title{
Urbanisation is associated with prevalence of childhood asthma in diverse, small rural communities in Ecuador
}

\author{
Alejandro Rodriguez, ${ }^{1,2}$ Maritza Vaca, ${ }^{1,2}$ Gisela Oviedo, ${ }^{1}$ Silvia Erazo, ${ }^{1}$ Martha E Chico, ${ }^{1}$ \\ Carlos Teles, ${ }^{2}$ Mauricio L Barreto, ${ }^{2}$ Laura C Rodrigues, ${ }^{3}$ Philip J Cooper ${ }^{1,4,5,6}$
}

\section{See Editorial, p 1025}

- Additional materials are published online only. To view these files please visit the journal online (http://thorax.bmj. com)

${ }^{1}$ Laboratorio de Investigaciones FEPIS, Quinindé, Esmeraldas, Ecuador

${ }^{2}$ Instituto de Saúde Coletiva, Universidade Federal da Bahia, Salvador, Bahia, Brazil

${ }^{3}$ Department of Epidemiology, London School of Hygiene and Tropical Medicine, London, UK ${ }^{4}$ Molecular and Biochemical Parasitology, Liverpool School of Tropical Medicine, Liverpool, UK ${ }^{5}$ Colegio de Ciencias de la

Salud, Universidad San

Fransisco de Quito

${ }^{6}$ Centre for Infection, St George's University of London, London, UK

\section{Correspondence to}

Professor Alejandro Rodríguez. Centro de Investigaciones FEPIS (Fundación Ecuatoriana para la Investigación en Salud), Quinindé, Esmeraldas, Ecuador; rodriguez_alej01@hotmail.com

Received 19 March 2011 Accepted 13 June 2011 Published Online First 8 August 2011

\section{ABSTRACT \\ Background Studies conducted in transitional} communities from Africa and Asia have pointed to the process of urbanisation as being responsible for the increase in asthma prevalence in developing regions. In Latin America, there are few published data available on the potential impact of urbanisation on asthma prevalence. The aim of the present study was to explore how the process of urbanisation may explain differences in asthma prevalence in transitional communities in north-eastern Ecuador.

Methodology/principal findings An ecological study was conducted in 59 communities in Esmeraldas Province, Ecuador. Indicators of urbanisation were grouped into three indices representing the processes associated with urbanisation: socioeconomic, lifestyle and urban infrastructure. Categorical principal components analysis was used to generate scores for each index and a fourth index - a summary urbanisation index-was derived from the most representative variables in each of the three indices. The authors analysed the associations between community asthma prevalence and the indices, as well as with each indicator variable of every group. The overall prevalence of asthma was $10.1 \%$ (range $0-31.4 \%$ between communities). Three of the four indices presented significant associations with community asthma prevalence: socioeconomic $(r=0.295, p=0.023)$, lifestyle $(r=0.342, p=0.008)$ and summary urbanisation index $(r=0.355, p=0.006)$. Variables reflecting better socioeconomic status and a more urban lifestyle were associated with greater asthma prevalence.

Conclusions These data provide evidence that the prevalence of asthma increases with increasing levels of urbanisation in transitional communities, and factors associated with greater socioeconomic level and changes towards a more urban lifestyle may be particularly important.

\section{INTRODUCTION}

Differences have been observed in asthma prevalence between and within countries with different levels of development, with greater asthma prevalence in developed countries and in urban areas of developing countries. ${ }^{12}$ However, these differences may have diminished over the past decade because asthma prevalence may have reached a plateau in some developed countries while continuing to rise in urban and perhaps rural areas of developing

\section{Key messages}

What is the key question?

- This paper addresses the question of why the prevalence of asthma is increasing in populations living in developing countries, particularly in Latin America.

\section{What is the bottom line?}

- Although the causes of this increase are poorly understood and are likely to be explained by a complex set of causal factors, we believe that the process of urbanisation may explain, at least partly, these temporal trends. No studies to date have investigated how the various processes associated with urbanisation may affect asthma prevalence.

\section{Why read on?}

- Our findings show how these processes extend into rural communities undergoing the transition from a traditional to a modern mode of life in a developing country and show how urbanisation and specific factors involved in this process are associated with asthma prevalence even in the rural tropics.

- Our findings are, therefore, likely to be of general relevance to those interested in the potential role of urbanisation in explaining asthma prevalence in the developing world.

countries. ${ }^{3}$ The causes of these variations are poorly understood and may be explained by a complex set of causal factors relating to changes in environment and lifestyle. ${ }^{45}$

Evidence from epidemiological studies suggests that the increase in asthma prevalence in developing countries may be explained by changes from traditional/rural to modern/urban societies. ${ }^{6} 7$ Rural areas tend to have a low asthma prevalence and this has been explained by the protection against allergic diseases provided by factors associated with a traditional rural lifestyle. ${ }^{8}$ However, numerous exposures related to urbanisation have been identified as potential risk factors for asthma (eg, reduction in the frequency of infections; reduction in family size; increasing vaccine coverage and use of antibiotics; increases in environmental pollution and household exposure to 
allergens; changes in diet, lifestyle and socioeconomic factors). ${ }^{5} 8$ There is evidence that the prevalence of allergic diseases is increasing with increasing levels of urbanisation. ${ }^{10}$ Nevertheless, such studies have not explored in detail which elements of the process of urbanisation are responsible, and there are no published studies evaluating the effects of urbanisation on asthma prevalence in Latin America. ${ }^{11} 12$

Urbanisation is defined as a gradual process of transformation where rural areas and their populations lose their rural characteristics and gradually become urban. ${ }^{13}$ This process occurs through improvements in urban infrastructure, public services, changes in social structures and lifestyle and population growth, among other factors. The present study developed indices of urbanisation to measure some of the factors that mould this process in transitional communities, and used these indices to explore how elements of the process of urbanisation may explain differences in asthma prevalence between small rural communities in a tropical region of Ecuador.

\section{METHODS}

\section{Study area and population}

The study was conducted in small rural communities in the districts of Eloy Alfaro and San Lorenzo in a humid tropical region of Esmeraldas Province in north-eastern Ecuador. Located in one of the poorest and remotest areas of the country, these communities have been undergoing changes related to urbanisation over the last 20 years. The principal economic activity of these communities is subsistence agriculture, hunting, fishing and logging. Employment through commerce and the provision of services is available in the larger communities. The educational level of the population is generally very low and rates of illiteracy among adults are high. Housing materials are generally wood and bamboo for walls and corrugated iron for roofing, although the use of cement blocks for walls is increasingly common. Drinking water comes directly from rivers, wells or rainwater, but some communities have piped but untreated water from streams. There is no municipal sewage system in any of the communities and disposal of faeces is by household or community pit latrines or in the open. A number of communities are connected to the national electrical grid but few have access to telephone services. Transportation for most communities is by river, although small roads are being built to interconnect some of these communities with the provincial capital of Esmeraldas. Temporary migration to the city of Esmeraldas and other urban centres in Ecuador is very frequent among people of working age. ${ }^{14}$

\section{Study design}

An ecological analysis was conducted using data collected from 59 communities. The original study was designed to investigate individual risk factors for allergy and asthma in Afro-Ecuadorian children and has been described in detail. ${ }^{15}$ Communities with a predominantly Afro-Ecuadorian population were included and all children aged $7-15$ years registered in a community census were eligible. The mean number of children evaluated in the communities was 73 children (range 15-331).

\section{Data collection}

Data were collected between May 2005 and March 2008. Data on asthma symptoms and risk factors including relevant lifestyle and socioeconomic factors were collected using a parentally administered questionnaire adapted from the International Study of Asthma and Allergies in Childhood phase II. ${ }^{16}$ Data on urban infrastructure characteristics were collected using a checklist.

\section{Prevalence of asthma}

Asthma was defined as a positive response to the question 'Has your child had wheeze in the chest in the last 12 months'. Prevalence of asthma was defined for each community as the number of children with wheeze in the past 12 months by the number of children aged 7-15 evaluated in each community.

\section{Measures of urbanisation}

We selected variables into three different groups of indicators (infrastructure, socioeconomic and lifestyle factors) to represent some of the main characteristics of the process of urbanisation in transitional communities (online supplement, table 1). The indicators used for each of these three groups are shown in table 1. Infrastructure indicators represent the 'urban' infrastructure of each community based on the presence of general basic services (online supplement, table 2). These variables were collected for each community. Socioeconomic indicators represent the socioeconomic status of the households in the communities based on indicators such as the presence of material possessions, access to general services, parental education, household income. The third group represents the acquisition of new lifestyle behaviours by the study population based on personal habits and general household characteristics. Data for the last two groups were presented as averages or proportions per community using data collected at the individual or household levels.

\section{Statistical analysis}

We calculated indices for each of the three groups and a summary urbanisation index using Categorical Principal Component Analysis (CATPCA), a multivariate technique that summarises a group of correlated variables (numeric, nominal or ordinal) in a single component group or independent index. ${ }^{17}{ }^{18}$ In CATPCA, the first component explains the highest proportion of total variance in the data set. The second component accounts for the majority of variance not explained by the first component, and so on. The variables are related to each component through their component loadings that are measures of correlation ( -1 to 1 ) between each variable and the components. A larger component loading for a variable represents a greater contribution of that variable in the component. The components produce a score for each community that summarises the contribution of all variables in each component. This score works like an index providing a summary measure, a range of $z$ scores for each of the communities. Two components were retained for each analysis and the scores provided by these were used as indices. For the construction of the summary urbanisation index, those variables with the highest component loadings for each of the three group analyses were included, also considering their theoretical relevance. Due to sample size and to avoid 'overloading', the summary urbanisation model kept the relationship of one variable to four observations. ${ }^{19}$ The urbanisation indices were interpreted such that higher values of component scores for each observation indicated a higher socioeconomic level, a more urban lifestyle and greater urban infrastructure. Spearman's correlations were calculated to explore the relationships between the four indices and asthma prevalence.

We also analysed the associations between each constituent variable for each of the infrastructure, socioeconomic and lifestyle indicator groups and community asthma prevalence using bivariate and multivariate linear regression, weighted for the inverse of the variance of the mean of community sizes. For multivariate analyses, we constructed a model for each of the indicator groups introducing all variables of each group separately through backwards stepwise regression. The final models selected were those that explained the most variation in asthma prevalence between 
Table 1 Infrastructure, socioeconomic and lifestyle indicators: definitions and descriptive characteristics

\begin{tabular}{|c|c|c|c|c|c|c|c|}
\hline \multirow{5}{*}{$\begin{array}{l}\text { Index } \\
\text { Infrastructure } \\
\text { (General characteristics } \\
\text { of the communities) }\end{array}$} & \multicolumn{2}{|l|}{ Indicators } & \multicolumn{2}{|l|}{ Definition } & \multicolumn{2}{|c|}{ Categories } & $\mathbf{N}(\%)$ \\
\hline & \multirow{2}{*}{\multicolumn{2}{|c|}{ Administrative grade }} & \multirow{2}{*}{$\begin{array}{l}\text { Measures the level of development based on the political/ } \\
\text { administrative division of the communities }\end{array}$} & \multicolumn{3}{|c|}{ Towns } & $42(71.2)$ \\
\hline & & & & & Parish & & $17(28.8)$ \\
\hline & \multirow{3}{*}{\multicolumn{2}{|c|}{ Spatial organisation }} & \multirow{3}{*}{$\begin{array}{l}\text { Used as a proxy variable for population density. This indicator } \\
\text { identifies the concentration of houses }\end{array}$} & & \multicolumn{2}{|c|}{ Dispersed } & $33(55.9)$ \\
\hline & & & & & \multicolumn{2}{|c|}{ Blocks } & 20 (33.9) \\
\hline & & & & & \multicolumn{2}{|c|}{ Neighbourhoods } & $6(10.2)$ \\
\hline & \multirow{2}{*}{\multicolumn{2}{|c|}{ Transport access }} & \multirow[t]{2}{*}{ Identifies the type of access used to arrive at communities } & & \multicolumn{2}{|l|}{ River } & $40(67.8)$ \\
\hline & & & & & Road & & $19(32.2)$ \\
\hline & \multirow{2}{*}{\multicolumn{2}{|c|}{ Electrical grid }} & \multirow[t]{2}{*}{ Identifies the presence of a connection to the electrical grid } & & \multicolumn{2}{|l|}{ Yes } & $41(69.5)$ \\
\hline & & & & & No & & $18(30.5)$ \\
\hline & \multirow{2}{*}{\multicolumn{2}{|c|}{ Piped water system }} & \multirow{2}{*}{$\begin{array}{l}\text { Identifies the presence of a piped water system (untreated } \\
\text { water only) }\end{array}$} & & \multicolumn{2}{|l|}{ Yes } & $12(20.3)$ \\
\hline & & & & & No & & $47(79.7)$ \\
\hline & \multirow{2}{*}{\multicolumn{2}{|c|}{ Telephone system }} & \multirow{2}{*}{$\begin{array}{l}\text { Identifies the presence of access to the national telephone } \\
\text { network }\end{array}$} & & Yes & & $17(28.8)$ \\
\hline & & & & & No & & $42(71.2)$ \\
\hline & Health centr & & Identifies the presence of a health centre & & Yes & & $17(28.8)$ \\
\hline & & & & & No & & $42(71.2)$ \\
\hline & Pharmacy & & Identifies the presence a pharmacy & & Yes & & $19(67.8)$ \\
\hline & & & & & No & & $40(32.2)$ \\
\hline & Educational & nstitution & Identifies the presence of secondary schools & & Yes & & $13(22.0)$ \\
\hline & & & & & No & & $46(78.0)$ \\
\hline & Shops & & Estimates the commercial infrastructure through number & & $0-1$ & & $16(27.1)$ \\
\hline & & & of shops & & $2-5$ & & $22(37.3)$ \\
\hline & & & & & $6-15$ & & $14(23.7)$ \\
\hline & & & & & $>15$ & & $7(11.9)$ \\
\hline Index & Indicators & Definitior & & Minin & um (\%) & Mean (\%) & Maximum (\%) \\
\hline $\begin{array}{l}\text { Socioeconomics } \\
\text { (\% households by }\end{array}$ & Father's education & $\begin{array}{l}\text { Estimates } \\
\text { secondar }\end{array}$ & $\begin{array}{l}\text { centage of households in which the father has any } \\
\text { ion }\end{array}$ & 0 & & 17.8 & 40.7 \\
\hline community) & Mother's education & $\begin{array}{l}\text { Estimates } \\
\text { secondar }\end{array}$ & $\begin{array}{l}\text { centage of households in which the mother has any } \\
\text { ion }\end{array}$ & 0 & & 19.4 & 47.8 \\
\hline & Household income & $\begin{array}{l}\text { Estimates } \\
\text { above US }\end{array}$ & $\begin{array}{l}\text { centage of households with an income equal or } \\
\text { onth }\end{array}$ & 0 & & 16.5 & 53.5 \\
\hline & Access to electricity & $\begin{array}{l}\text { Estimates } \\
\text { (electrica }\end{array}$ & $\begin{array}{l}\text { centage of households with electricity } \\
\text { generator) }\end{array}$ & 0 & & 68.3 & 100 \\
\hline & Material goods & $\begin{array}{l}\text { Estimates } \\
\text { TV and } s\end{array}$ & $\begin{array}{l}\text { centage of households with (all of) refrigerator, } \\
\text { tem }\end{array}$ & 0 & & 14.4 & 42.4 \\
\hline & Cement house & Estimates & centage of households with cement walls & 0 & & 12.3 & 48.2 \\
\hline & Gas for cooking & Estimates & centage of households that use propane gas for cooking & 0 & & 63.3 & 100 \\
\hline & Motor vehicles & Estimates & centage of households with motor vehicles (boat or car) & 0 & & 10.1 & 48.2 \\
\hline & Uncrowded household & $\begin{array}{l}\text { Estimates } \\
\text { by bedroc }\end{array}$ & centage of households that are not crowded ( $\leq 3$ persons & 15.8 & & 58.8 & 89.7 \\
\hline $\begin{array}{l}\text { Lifestyle (\% study } \\
\text { children or household }\end{array}$ & $\begin{array}{l}\text { Consumption } \\
\text { of hamburgers }\end{array}$ & $\begin{array}{l}\text { Estimates } \\
\text { at least } 0\end{array}$ & $\begin{array}{l}\text { centage of the study children who consume hamburgers } \\
\text { onth }\end{array}$ & 0 & & 21.1 & 58.3 \\
\hline by community) & $\begin{array}{l}\text { Consumption of } \\
\text { fizzy drinks }\end{array}$ & Estimates & centage of the study children who consume fizzy drinks daily & 0 & & 17.4 & 88.0 \\
\hline & No physical exercise & $\begin{array}{l}\text { Estimates } \\
\text { daily (pro }\end{array}$ & $\begin{array}{l}\text { centage of the study population that do no physical activity } \\
\text { dentarism) }\end{array}$ & 0 & & 25.6 & 65.6 \\
\hline & Television in house & Estimates & centage of houses that have a television & 0 & & 55.5 & 96.6 \\
\hline & TV viewing & Estimates & centage of the study children who watch television $>1 \mathrm{~h}$ daily & 0 & & 65.9 & 100 \\
\hline & No farming activities & Estimates & centage of households that do not work in agricultural activities & 0 & & 11.8 & 68 \\
\hline & Cat in house & Estimates & centage of households that have a cat living inside the house & 0 & & 34 & 81.5 \\
\hline & Dog in house & Estimates & centage of households that have a dog living inside the house & 4.2 & & 52.6 & 96 \\
\hline & Migration & $\begin{array}{l}\text { Estimates } \\
3 \text { months }\end{array}$ & $\begin{array}{l}\text { centage of the study children who has lived for at least } \\
\text { the study area in the past }\end{array}$ & 3.9 & & 29.8 & 76 \\
\hline & Parasite infection rate & $\begin{array}{l}\text { Percentas } \\
\text { Trichuris }\end{array}$ & $\begin{array}{l}\text { ulation with intestinal helminth Ascaris lumbricoides, } \\
\text { Strongyloides stercoralis }\end{array}$ & 14 & & 76.3 & 100 \\
\hline
\end{tabular}

communities and were those with the smallest mean square error and the highest value of adjusted $\mathrm{R}^{2}{ }^{20}$ For bivariate analyses, variables with $\mathrm{p}<0.10$ were considered relevant and statistically significant associations in the multivariate models were inferred by $p<0.05$. Calculations were done with and without outliers and extreme observations of the asthma prevalence; given that results were very similar, we present results with all observations. All the analyses were carried out with SPSS V.15.

\section{RESULTS}

Based on local updated censuses, we sampled approximately $95 \%$ of the eligible population or 4183 children. The overall prevalence of asthma was $10.1 \%$ (range $0-31.4 \%$ ). The indicator variables considered for infrastructure, socioeconomic and lifestyle indices are provided in table 1 together with frequencies and mean values where appropriate, showing significant heterogeneity between communities. 
Table 2 Component loadings by infrastructure, socioeconomic and lifestyle indices

\begin{tabular}{|c|c|c|c|c|c|}
\hline \multirow[b]{2}{*}{ Groups } & \multirow[b]{2}{*}{ Indicators } & \multicolumn{2}{|c|}{ Components loading by group } & \multicolumn{2}{|c|}{$\begin{array}{l}\text { Components loading for } \\
\text { summary urbanisation index }\end{array}$} \\
\hline & & Component 1 & Component 2 & Component 1 & Component 2 \\
\hline \multirow[t]{11}{*}{ Infrastructure } & Administrative grade & 0.611 & -0.337 & & \\
\hline & Spatial organisation & 0.753 & -0.420 & 0.530 & 0.664 \\
\hline & Transport access & 0.741 & 0.188 & & \\
\hline & Electrical grid & 0.449 & 0.764 & & \\
\hline & Piped water system & 0.746 & 0.016 & & \\
\hline & Telephone system & 0.762 & 0.252 & 0.696 & 0.348 \\
\hline & Health centre & 0.875 & 0.021 & 0.678 & 0.507 \\
\hline & Pharmacy & 0.681 & 0.138 & & \\
\hline & Educational institution & 0.785 & -0.337 & 0.511 & 0.684 \\
\hline & Shops & 0.877 & -0.015 & 0.746 & 0.461 \\
\hline & $\%$ of variance & 54.4 & 11.1 & & \\
\hline \multirow[t]{10}{*}{ Socioeconomic } & Father's education & 0.658 & -0.436 & & \\
\hline & Mother's education & 0.768 & -0.268 & 0.736 & 0.220 \\
\hline & Household income & 0.821 & -0.184 & 0.790 & 0.095 \\
\hline & Access to electricity & 0.787 & 0.187 & 0.736 & -0.486 \\
\hline & Material goods & 0.854 & -0.005 & 0.816 & -0.172 \\
\hline & Cement house & 0.705 & 0.143 & & \\
\hline & Gas for cooking & 0.834 & 0.304 & 0.808 & -0.363 \\
\hline & Motor vehicles & 0.456 & 0.692 & & \\
\hline & Uncrowded household & 0.255 & 0.662 & & \\
\hline & $\%$ of variance & 50.1 & 15.1 & & \\
\hline \multirow[t]{11}{*}{ Lifestyle } & Consumption of hamburgers & 0.837 & -0.269 & 0.763 & -0.262 \\
\hline & Consumption of fizzy drinks & 0.749 & 0.080 & 0.654 & -0.312 \\
\hline & No physical exercise & 0.672 & -0.522 & & \\
\hline & Television in house & 0.849 & 0.259 & 0.873 & -0.344 \\
\hline & TV viewing & 0.889 & 0.061 & 0.820 & -0.419 \\
\hline & No farming activities & 0.663 & 0.542 & 0.757 & -0.038 \\
\hline & Cat in house & 0.646 & 0.382 & & \\
\hline & Dog in house & 0.595 & -0.398 & & \\
\hline & Migration & 0.793 & -0.193 & & \\
\hline & Parasite infection rate & 0.036 & 0.732 & & \\
\hline & $\%$ of variance & 50.7 & 15.9 & 54.0 & 16.0 \\
\hline
\end{tabular}

CATPCA results are provided in table 2 . Most indicator variables showed high loadings $(>0.6)$ for the first components with Cronbach's $\alpha>0.85$. The total variance explained by the first component for infrastructure, socioeconomic and lifestyle indices was $54.4 \%, 50.1 \%$ and $50.7 \%$, respectively. Five indicators were selected from each group to be included in the summary urbanisation index (table 2): those with the highest component loadings for each group with a single exception 'No agricultural activity', which was included because of its theoretical importance in distinguishing rural from urban populations. ${ }^{13}$ The first component of the summary analysis accounted for $54.0 \%$ of total variation, and 13/15 variables had factor loadings $>0.6$. The associations between the four indices and asthma prevalence are illustrated in figure 1. Significant correlations $(p<0.05)$ with asthma prevalence were observed for three of the four indices: socioeconomic $(r=0.295)$, lifestyle $(r=0.342)$ and summary urbanisation index $(\mathrm{r}=0.355)$. There was a weak association between the urban infrastructure index and asthma prevalence (table 3 ). The summary urbanisation index showed high correlations with the other three indices $(>0.840)$ that were highly correlated (table 3).

The results of bivariate analyses between indicator variables for each index and asthma prevalence are shown in table 4. Bivariate analyses for infrastructure indicators showed that electrical grid $(\beta=2.226)$, healthcare centre $(\beta=2.076)$ and community pharmacy $(\beta=2.296)$ were associated with asthma prevalence $(p<0.10)$. In the multivariate analysis for this group,
$3 / 10$ variables were kept in the final model $(\mathrm{p}<0.05)$, explaining $17.7 \%$ of variability in asthma prevalence across communities (adjusted $\left.\mathrm{R}^{2}=0.177 ; \mathrm{p}=0.008\right)$ : presence of access roads ( $\beta=-6.069)$, presence of electrical grid $(\beta=5.117)$ and number of shops (>15/shops: $\beta=5.065$ ). Thus, asthma prevalence decreased $6.1 \%$ in communities with roads compared with river access; asthma prevalence increased $5.1 \%$ for communities with an electric grid connection compared with those without; and asthma prevalence increased $5.1 \%$ for those communities with more than 15 shops compared with those with $0-1$ shops. Bivariate analyses for socioeconomic indicators showed that asthma prevalence was associated with household income $(\beta=0.072)$, having access to electricity $(\beta=0.029)$, number of household material goods $(\beta=0.104)$, use of gas for cooking $(\beta=0.046)$ and having a motor vehicle $(\beta=0.164)$. In the multivariate analysis, 5/9 indicators remained in the final model, explaining $17.4 \%$ of variability in asthma prevalence across communities (adjusted $\mathrm{R}^{2}=0.174 ; \mathrm{p}=0.009$ ), of which three were statistically associated: having access to electricity $(\beta=0.045)$, having a cement house $(\beta=-0.127)$ and having a motor vehicle $(\beta=0.168)$. Thus, in the multivariate model, asthma prevalence increased $4.5 \%$ if all households had access to electricity, increased $16.8 \%$ if all households had motor vehicles, but decreased $12.7 \%$ if all households were cement-built. Bivariate analyses for lifestyle indicators showed associations with: consumption of hamburgers $(\beta=0.104)$ and fizzy drinks ( $\beta=0.121)$, watching TV daily $(\beta=0.048)$, no agricultural 
Figure 1 Scatter plots of the relationships between community asthma prevalence (measured by the proportion of children with wheezing in the last 12 months) and $\mathrm{z}$ scores for the first components of infrastructure $(A)$, socioeconomic (B), lifestyle (C) and summary urbanisation (D) indices. The regression line is shown for each relationship. Red squares represent outliers and extreme observations identified on residual analysis in bivariate linear regression.
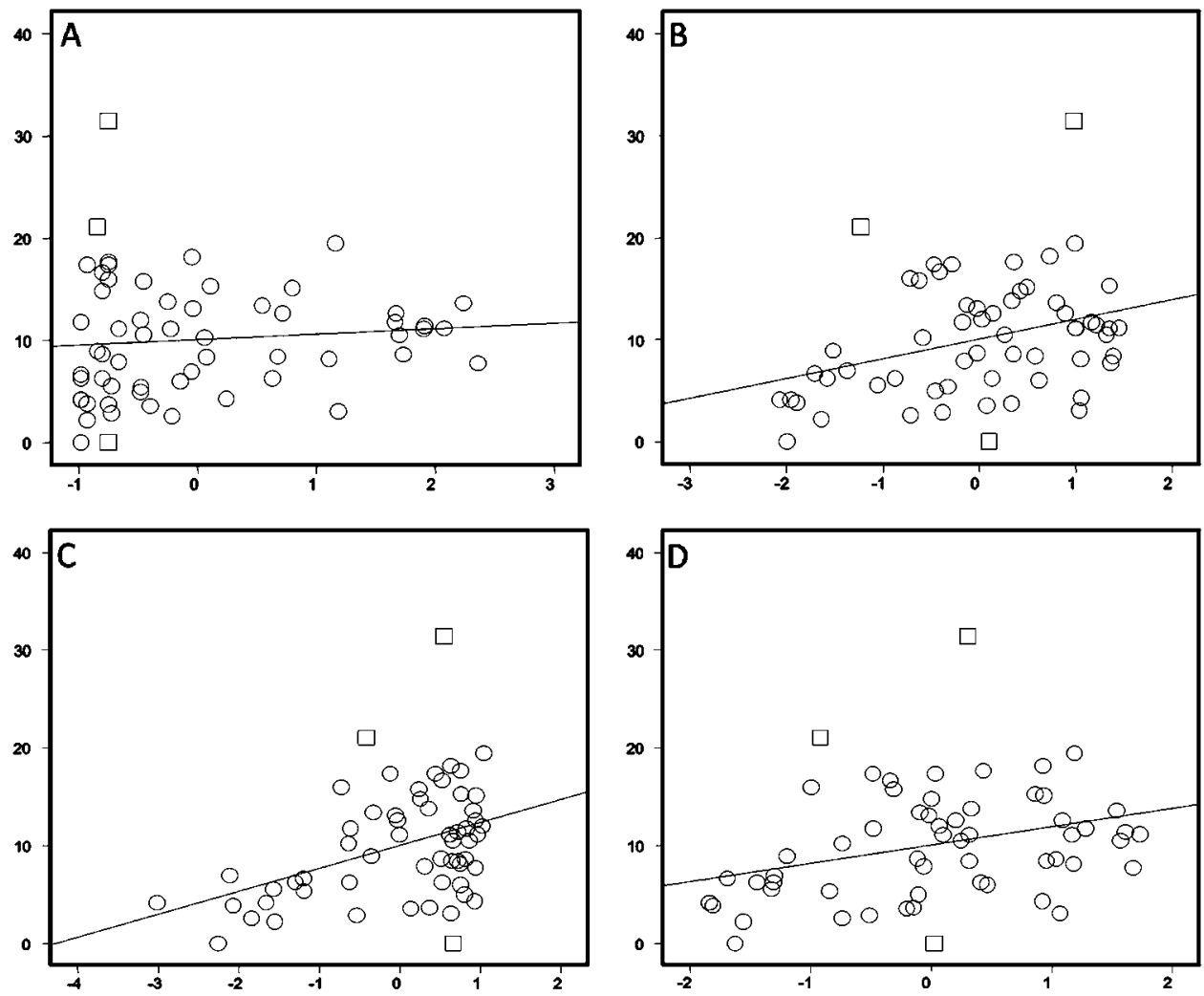

activity $(\beta=0.065)$ and having a household cat $(\beta=0.091)$. In the multivariate analysis, $5 / 10$ lifestyle indicators remained in the final model, explaining $19.8 \%$ of variability in asthma prevalence (adjusted $\left.\mathrm{R}^{2}=0.198 ; \mathrm{p}=0.005\right)$, of which consumption of fizzy drinks was statistically significant $(\beta=0.132)$.

\section{DISCUSSION}

In the present study, we conducted an ecological analysis to understand better if urbanisation (and specific factors associated with this process) may explain the variation in asthma prevalence between rural transitional communities. Clearly, urbanisation is a highly complex process and is strongly associated with other aspects of modernisation, especially in developing countries. We chose to measure urbanisation by exploring variables representative of infrastructure, socioeconomic and lifestyle indicators that together constitute much of what is understood by urbanisation. A population does not have to live in an urban environment to experience many of the processes associated with urbanisation and the effects of individual factors that constitute urbanisation on asthma prevalence may be more clearly measured in transitional societies where there is likely to be sufficient heterogeneity in exposure to such factors.

Cross-sectional studies conducted in developing countries have shown a higher prevalence of asthma reported in urban compared with rural populations, although the magnitude of the difference is variable: South Africa (urban $=33.0 \%$, periurban $=34.4 \%$; rural=17.0\%), Zimbabwe (urban rich $=5.8 \%$; urban poor $=3.1 \%$; rural $=0.1 \%$ ), Ethiopia (urban $=3.6 \%$, rural $=1.6 \%$ ), Ghana (urban rich $=4.7 \%$, urban poor $=2.2 \%$, rural $=1.4 \%$ ), Kenya (urban $=22.9 \%$, rural $=13.2 \%$ ) and Saudi Arabia (urban $=14.9 \%$, rural $=5.4 \%$ ). ${ }^{21-26}$ Similarly, crosssectional studies conducted at different times have provided evidence for temporal increases in the prevalence of asthma in both urban and rural populations, ${ }^{27} 28$ although the urban-rural difference in asthma prevalence may be narrowing. ${ }^{1029}$ Previous ecological studies have compared asthma prevalence between cities $^{20}$ within a country or between countries represented by one or more cities. ${ }^{2}$ Inter-country comparisons such as the International Study of Asthma and Allergies in Childhood ${ }^{2}$ are unlikely to provide useful insights into the effects of urbanisation on asthma prevalence given that most study centres were in cities and different countries are likely to have different experiences of the individual urbanisation processes. Intra-country comparisons may be more useful: an ecological comparison between several cities in Brazil found that asthma prevalence was greater in cities with more poverty and inequality. ${ }^{20}$

The present study, which compared small rural communities, had significant heterogeneity in the levels of exposure to the

Table 3 Associations between community asthma prevalence and urbanisation indices

\begin{tabular}{|c|c|c|c|c|c|c|c|c|}
\hline \multirow[b]{2}{*}{ Indices } & \multicolumn{2}{|c|}{ Asthma prevalence } & \multicolumn{2}{|c|}{ Infrastructure } & \multicolumn{2}{|c|}{ Socioeconomic } & \multicolumn{2}{|c|}{ Lifestyle } \\
\hline & $\mathbf{r}$ & $\mathbf{p}$ & $\mathbf{r}$ & $\mathbf{p}$ & $\mathbf{r}$ & $\mathbf{p}$ & $\mathbf{r}$ & $\mathbf{p}$ \\
\hline Infrastructure & 0.173 & 0.190 & 1 & - & - & - & - & - \\
\hline Socioeconomic & 0.295 & 0.023 & 0.757 & $<0.001$ & 1 & - & - & - \\
\hline Lifestyle & 0.342 & 0.008 & 0.671 & $<0.001$ & 0.819 & $<0.001$ & 1 & - \\
\hline Summary urbanisation & 0.355 & 0.006 & 0.840 & $<0.001$ & 0.937 & $<0.001$ & 0.895 & $<0.001$ \\
\hline
\end{tabular}

Results shown are Spearman's rank correlation coefficients. 
Table 4 Associations between community asthma prevalence and individual indicators of infrastructure, socioeconomic and lifestyle indices

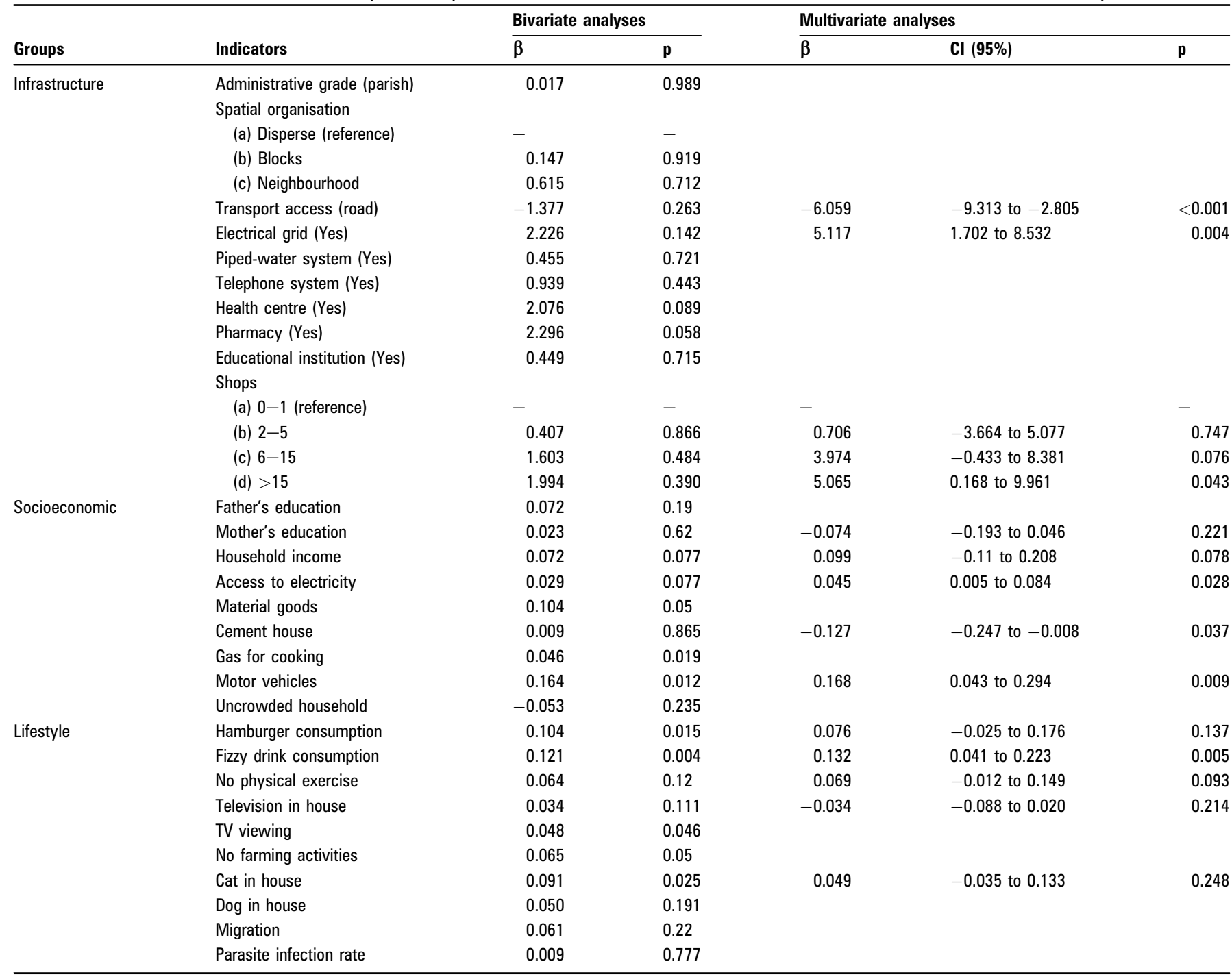

Results shown are for bivariate and multivariate linear regression analyses.

urbanisation indicators between communities and was able to measure the potential effects of these indicators on asthma prevalence. The study was able to demonstrate that lifestyle indicators and socioeconomic indicators had stronger overall effects on asthma prevalence than infrastructure indicators (figure 1), indicating that a higher asthma prevalence was present in communities with a higher socioeconomic level and a more urbanised lifestyle. Indeed, asthma prevalence increased with increasing household income, access to electricity, material goods, gas for cooking and possession of motor vehicles. Our findings are consistent with the findings of other studies conducted in transitional communities that have shown an association between better socioeconomic status and asthma prevalence (ie, urban rich vs urban poor). ${ }^{22} 24$ Rural residence has been repeatedly shown to be protective against allergic diseases and this effect has been attributed to farming exposures. ${ }^{8}$ Consistent with these, communities with a higher percentage of households not involved in agricultural activities had a higher prevalence of asthma. Rates of parasite infection with geohelminth infections were not associated with asthma prevalence in our study population in agreement with the findings of previous studies. ${ }^{11} 30$ The increased consumption of fast foods such as hamburgers and soft drinks (that represent new food habits) was associated with greater asthma prevalence and is consistent with individual-level studies that have shown changes in diet of populations undergoing transition is associated with an increase in asthma. ${ }^{3132}$ Factors associated with a sedentary lifestyle such as limited physical activity and watching TV for more than $1 \mathrm{~h}$ daily were associated with greater asthma prevalence, and are consistent with the findings of previous studies. ${ }^{33} 34$ Somewhat paradoxically, ownership of motorised vehicles was associated with an increased asthma prevalence but road access with a decreased asthma prevalence. Road access does not necessarily mean a higher level of urbanisation than river access because most roads are dirt tracks with limited public transportation and accessible communities have few privately-owned vehicles. Communities with river access actually had higher levels of ownership of motor vehicles (motorised canoes), and such ownership could be associated, for example, with greater levels of environmental pollution with exhaust particulates, a potential mechanism mediating an increase in asthma.

The lifestyle index that showed the strongest association with the prevalence of asthma was also strongly associated with the other urbanisation indices. These relationships suggest that the growing influence of urban lifestyle on rural societies may explain at least partly the increase in asthma prevalence in rural 
populations and the declining gap between urban and rural asthma prevalence. This is illustrated in the present study by the high rates of television viewing, consumption of soft drinks and presence of material goods in some of the communities. The weak associations between the infrastructure index (and most indicators that constituted this index) with asthma prevalence might be related to the fact that in communities undergoing transition in developing countries some elements of the urbanisation process develop less faster than others changes (eg, social and consumption changes). ${ }^{13}$ For example, a high proportion of communities lacked basic services but had a high percentage of television ownership. The implementation of basic infrastructure and basic services tends to lag behind other urbanisation processes because of a lack of economic resources from highly centralised political establishments that are reluctant to invest in populations that do not represent their primary political constituencies. The disparities in the levels of urbanisation in developing countries could help explain the variation of asthma prevalence between and within countries of Latin America.

Our study findings from an ecological analysis are subject to some limitations. First, the associations observed at the community level may not reflect associations at the individual level (ecological fallacy). Despite the fact that we collected detailed information on urbanisation indicators, other data that are likely to be important (eg, environmental sampling for air pollution) were not available. Smoking was not included in our analysis because in the study area, a widespread traditional lifestyle habit is to smoke a traditional cigarette, 'cachimba', and thus smoking in the context of this study, given that we did not collect data to distinguish smoking of traditional versus modern cigarettes, is unlikely to be a useful explanatory variable for urbanisation. We defined asthma as having a wheeze in the previous 12 months. This is a widely used definition and has the advantage of simplicity, but of course not all wheezing is asthma. However, we believe that this definition is likely to be less subject to misclassification compared with other definitions (such as doctor diagnosis of asthma) used in rural populations with limited access to healthcare. Our analysis is limited in degree to which we can attribute urbanisation as being a causal factor for asthma prevalence-many of the variables included in our analysis are markers of lifestyle and while being associated with asthma prevalence may not necessarily be causal.

In conclusion, we have explored the effects of factors associated with urbanisation on the community prevalence of asthma in rural transitional communities in a developing country. Clearly, urbanisation is a complex process that comprises an array of changes that modify the living environment and human behaviours. The consequence of such changes that penetrate inexorably over time into rural environments may be to deprive urbanising populations of childhood exposures that are important for the development of normal airway function. Our data provide evidence that the process of urbanisation is associated with a greater prevalence of asthma in rural communities in Ecuador. The high level of socioeconomic inequality and the rapid but variable rate of urbanisation occurring in Latin America may explain temporal trends and differences in asthma prevalence in this region. ${ }^{35}$ To explore these findings better, future studies should pay attention to the social mechanisms and processes that modify the rural way of life towards an urban lifestyle.

Acknowledgements The Ecuadorian Elimination Programme for Onchocerciasis (Dr Eduardo Gomez, Dra. Raquel Lovato, Lcda. Margarita Padilla, Lcda Anabel Ponce, Lcda Ing Sandra Barrera, Magdalena Cortez) and CECOMET (Dr Gregorio Montalvo and Lcda Monica Marquez) are thanked for support in visiting communities and providing community censuses. The health promoters, school teachers, parents and children are thanked for their enthusiastic cooperation. The study forms part of the SCAALA (Social Changes, Asthma, and Allergies in Latin America) programme of research.

Funding Wellcome Trust, UK, HCPC Latin American Centres of Excellence Programme (ref 072405/Z/03/Z). The funders had no role in study design, data collection and analysis, decision to publish or preparation of the manuscript.

\section{Competing interests None.}

Ethics approval The study protocol was approved by the ethics committee of the Hospital Pedro Vicente Maldonado, Ecuador.

Contributors Study design: PJC, AR, MC, LCR, MLB. Data collection; AR, MV, GO, SE. Data analysis: AR,CT. Draft manuscript: AR, PJC. Manuscript review: AR, PJC, LR MLB.

Provenance and peer review Not commissioned; externally peer reviewed.

\section{REFERENCES}

1. Woolcock AJ, Peat JK. Evidence for the increase in asthma worldwide. Ciba Found Symp 1997;206:122-34.

2. Anon. Worldwide variation in prevalence of symptoms of asthma, allergic rhinoconjunctivitid, and atopic eczema: ISSAC. The international Study of Asthma and Allergies in Childhood ISAAC. Lancet 1998;351:1225-32.

3. Pearce N, Ait-Khaled N, Beasley R, et al. Worldwide trends in the prevalence of asthma symptoms: phase three of the International Study of Asthma and Allergies in Childhood (ISAAC). Thorax 2007:62:758-66.

4. Beasley R, Crane J, Lai CK, et al. Prevalence and etiology of asthma. J Allergy Clin Immunol 2000;105:S466-72.

5. Von Hertzen L, Haahtela T. Asthma and atopy—the price of affluence? Allergy 2004;59:124-37.

6. Weinberg EG. Urbanization and childhood asthma: an African perspective. Allergy Clin Inmunol 2000;105:224-31.

7. Singh M. The burden of asthma in children. An Asian perspective. Paediatr Respir Rev 2005;6:14-19.

8. Von Hertzen L, Haahtela T. Disconnection of man and the soil: reason for the asthma and atopic epidemic? Allergy 2006;117:334-44.

9. Nicolaou N, Siddique N, Custovic A. Allergic disease in urban and rural populations: increasing prevalence with increasing urbanization. Allergy 2005;60:1359-60.

10. Viinanen A, Munhbayarlah S, Narantsetseg L, et al. Prevalence of asthma, allergic rhinocongunctivitis and allergic sensitisation in Mongolia. Allergy 2005:60:1370-77.

11. Cooper PJ, Rodrigues LC, Cruz AA, et al. Asthma in Latin America: a public health challenge and research opportunity. Allergy 2009;64:5-17.

12. Fischer GB, Camargos PAM, Mocelin HT. The burden of asthma in children: a Latin American perspective. Pediatr Respir Rev 2005;6:8-13

13. Germani G. El proceso de urbanización en los países avanzados y en los países en desarrollo. In: Germani G, ed. Sociología de la Modernización. Buenos Aires: PAIDOS Press, 1971:146-76.

14. Caicedo CM. Documento de Diagnóstico del Área de Salud \# 7 Borbón. Cantón Eloy Alfaro provincia de Esmeraldas, 2004

15. Cooper PJ, Chico ME, Rodriguez A, et al. Risk factors for asthma and allergy associated with urban migration: background and methodology of a cross-sectional study in Afro-Ecuadorian school children in Northeastern Ecuador (EsmeraldasSCAALA Study). BMC Pulm Med 2006;6:24-31.

16. Weiland SK, Bjorksten B, Brunekreef B, et al. Phase II of the International Study of Asthma and Allergies in Childhood (ISAAC II): rationale and methods. Eur Respir J 2004:24:406-12

17. Maroco J. Análise de Componentes Principais. In: Maroco J, ed. Análise Estatistica-Com utilização do SPSS. Lisboa: Silabo Press, 2003:231-57.

18. Meulman J. Optimal Scaling Methods for Multivariate Categorical Data Analysis. Leiden: Leiden University, 2000

19. Hair JF, Anderson RE, Tathan RL, et al. Análise factorial. In Análise Multivariada de dados. Porto Alegre: Bookman Press, 2005:88-130.

20. Cunha SS, Pujades MR, Barreto ML, et al. Ecological study of socio-economic indicators and prevalence of asthma in schoolchildren in urban Brazil. BMC Public Health 2007; 7:205.

21. Steinman HA, Donson $H$, Kawalski $M$, et al. Bronchial hyper-responsiveness and atopy in urban, peri-urban and rural South African Children. Pediatr Allergy Immunol 2003:14:383-93.

22. Keeley DJ, Neill P, Gallivan S. Comparison of the prevalence of reversible airways obstruction in rural and urban Zimbabwean children. Thorax 1991;46:549-53.

23. Yemaneberhan $\mathbf{H}$, Bekele Z, Venn A, et al. Prevalence of wheeze and asthma and relation to atopy in urban and rural Ethiopia. Lancet 1997;350:85-90.

24. Addo Yobo E0, Custovic A, Taggart SC et al. Exercise induced bronchospasm in Ghana: differences in prevalence between urban and rural schoolchildren. Thorax 1997:52:161-5.

25. Ng'ang'a LW, Odhiambo JA, Mungai MW, et al. Prevalence of exercise induced bronchospasm in Kenyan school children: an urban-rural comparison. Thorax 1998:53:919-26.

26. Hijazi N, Abalkhail B, Seaton A. Asthma and respiratory symptoms in urban and rura Saudi Arabia. Eur Respir 1998;12:41-4. 
27. Van Niekerk CH, Weinberg EG, Shore SC, et al. Prevalence of asthma: a comparative study of urban and rural Xhosa children. Clin Allergy 1979;9:319-24.

28. Addo-Yobo E0, Woodcock A, Allotey A, et al. Exercise-induced bronchospasm and atopy in Ghana: two surveys ten years apart. PLoS Med 2007:4:e70.

29. Calvert J, Burney PGJ. Increase in prevalence of exercise induced bronchospasm in a rural and urban population of African school children. Curr Allergy Clin Immunol 2003;16:117.

30. Moncayo A, Vaca M, Oviedo G, et al. Risk factors for atopic and non atopic asthma in rural area of Ecuador. Thorax 2010;65:409-16.

31. Hijazi N, Abalkhail B, Seaton A. Diet and childhood asthma in a society in transition: a study in urban and rural Saudi Arabia. Thorax 2000;55:775-9.
32. Hooper $\mathbf{R}$, Calvert J, Thompson RL, et al. Urban/rural differences in diet and atopy in South Africa. Allergy 2008;63:425-31.

33. Jones SE, Merkle SL, Fulton JE, et al. Relationship between asthma, overweight, and physical activity among U.S. high school students. J Community Health 2006;31:469-78

34. Firrincieli V, Keller A, Ehrensberger $R$, et al. Decreased physical activity among Head Start children with a history of wheezing: use of an accelerometer to measure activity. Pediatr Pulmonol 2005; 40:57-63.

35. Asher MI, Montefort S, Björkstén B, et al: The ISSAC Phase three Study Group. Worldwide time trends in the prevalence of symptoms of asthma, allergic rhinoconjunctivitis, and eczema in childhood: ISAAC Phases One and Three repeat multicountry cross-sectional surveys. Lancet 2006;368:733-43.

\section{SAVE TIME AND KEEP INFORMED}

\section{Thorax}

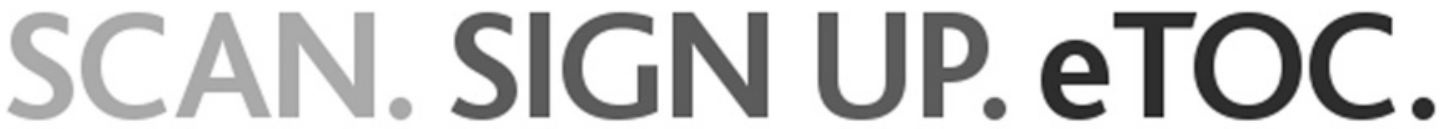

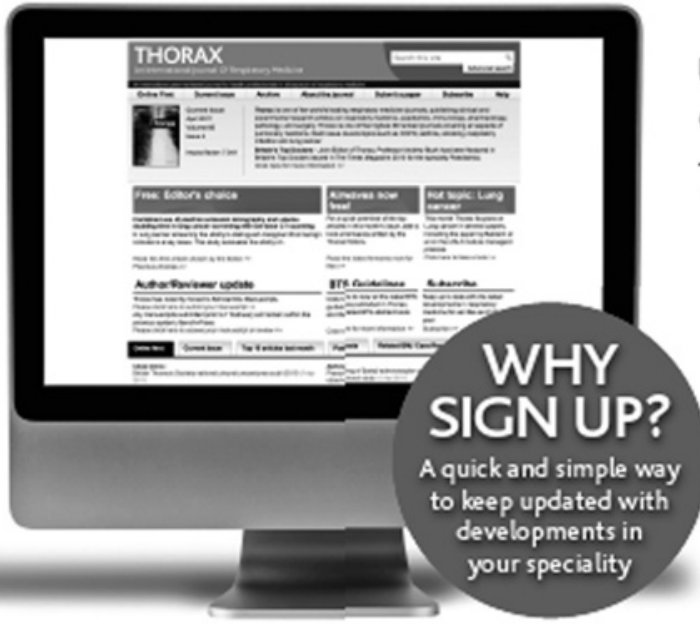

thorax.bmj.com
Utilise our Quick Response code (QR) to sign up for our electronic table of contents (eTOC) alert.

To make this simple you can sign up now via your Smartphone.

\section{FOLLOWTHESE}

THREE EASY STEPS:

1. Download a free $Q R$ reader from your

handset's app store

2. Hold your Smartphone over the QR code

3. You will then be forwarded to the eTOC sign up page

To find out more about $Q R$ codes visit

group.bmj.com/products/journals/qr-codes 